INTERNATIONAL JOURNAL OF RESEARCHES IN BIOSCIENCES, AGRICULTURE AND TECHNOLOGY (C) VISHWASHANTI MULTIPURPOSE SOCIETY (Global Peace Multipurpose Society) R. No. MH-659/13(N) www.ijrbat.in

\title{
APPLICATION OF NATURAL DYE FROM THESPESIA POPULNEA, SOLAND. IN COTTON INDUSTRY TO PREVENT POLLUTION.
}

\author{
Patale M. W \\ Department of Botany, S. P. College, Pune 411030. \\ Corresponding author: mwpatale@gmail.com

\section{Abstract:} \\ India has a rich biodiversity and harbours wealth of useful Germplasm resources and there is no doubt, that the \\ plant kingdom is treasure house of diverse natural products, one such product from nature is dye. Dye is one of \\ the most important resources from plant [1]. Recently, interest in use of natural dyes has been growing rapidly due \\ to toxic and allergic reaction associated with synthetic dyes. In nature there are more than 500 dyes yielding plant \\ species [3]. Allplant based pigments have medicinal values so are mostly preferred. Two different methods for \\ extraction of dye from collected fruit were evaluated to determine the best method.
}

Keywords: Pollution, Natural dyes.

\section{Introduction}

Dyeing of textiles means giving them a colour which is of comparative permanence. In ancient times popular natural dyes were known as indigo for light or dark blue, lac for scarlet red etc. Research have shown that synthetic dyes are suspected to release harmful chemicals that are allergic, carcinogenic and detrimental to human health, on the other hand natural dyes are ecofriendly. Nature has gifted us with more than 500 dye yielding plant species [1], one such plant used for dying is Thespesia populnea, Soland. (Family Malvaceae), commonly called as pimarani and parasa bhendi. It is a small tree or arborescent shrub. That has pan tropical distribution, found on coast around the world. Due its ability to undergo carving, its wood is mainly used for making furniture. The plant is mainly used on ulcers, inflammation, skin diseases, ringworm and joint effusion..

\section{Materials and Methods}

The dye was extracted from fresh fruits of Thespesia populnea, Soland. (Family Malvaceae), collected from Sinhgad road, Pune.

\section{Dye Extraction}

In this method Fresh fruits were used for extraction .Dye from fruit was extracted by preparing aqueous solution and the process was carried out at $85^{\circ} \mathrm{C}$ for one hour. Colouring material from fruit was extracted for dyeing of fabric.

\section{Dyeing procedure:}

The extract obtained was filtered. Dyeing was done by two methods. In the first method cotton cloth used for dyeing was boiled in $\mathrm{NaOH}$ solution for 15 minutes. Then cloth was washed with cold distilled water. After that cotton cloth was transferred to myrabalan aqueous extract, which was used as amordant for 30 minutes and then the cloth was dipped in dye for one hour. After 1 hour egg yolk and vinegar were added. Egg yolk worked as colour fixative and vinegar was added to reduce the smell of yolk. Then it was sundried for two hours.

In second method the cotton cloth was treated with $10 \%$ of $\mathrm{NaOH}$ solution for 15 minutes. After that washed with cold distilled water. Then the cloth was transferred to myrabalan in dye extract and kept it for 30 minutes. Then it is sundried for two hours.

Sundried cloth was further evaluated for its colour, lightness and wash fastness. Wash fastness was tested by washing with soap water.

$$
\text { Cotton cloth }(10 \times 10 \mathrm{~cm}) \text {. }
$$<smiles>c1ccccc1</smiles>

Cloth boiled in $\mathrm{NaOH}$ solution (10\%) for 15 minutes

Wash with cold distilled water

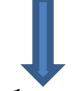

Transfer in mordant (myrabalan) for 30 minutes

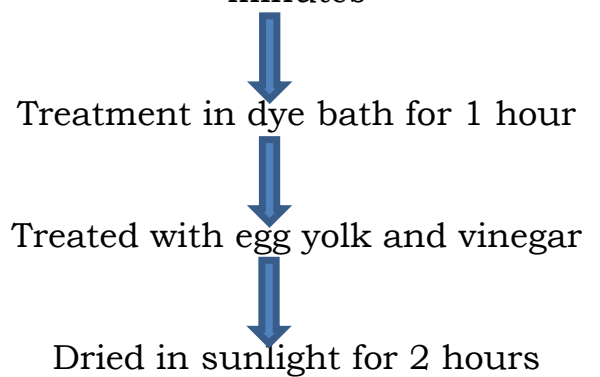

Dried in sunlight for 2 hours

Evaluated for colour, brightness and wash fastness 


\section{Result and Discussion:}

A dark yellowish -brown dye was obtained from fruit of Thespesia populnea, Soland. (Family Malvaceae), by second method. Effect of myrabalan and dye colour was seen in second method of extraction. Cotton cloth dyed by first method was light brown whereas, by second method cloth colour observed was yellowish brown.

Herbal dyes being natural tend to be softer and their range of tones is very pleasant [1]. India is a major exporter of herbal dyes mostly due to ban on production of some of the synthetic dyes and intermediate in the developed countries due to pollution problems. The application of natural dyes in textile industry for various purposes, viz. dyeing of yarns, which are then woven into cloths, carpet, block printing [1].

The present work shows that these fruits can be used as dye quite efficiently. We can get different shades of colour using different mordant and colour fastness, wash fastness, properties also can be improved by different treatment procedure.

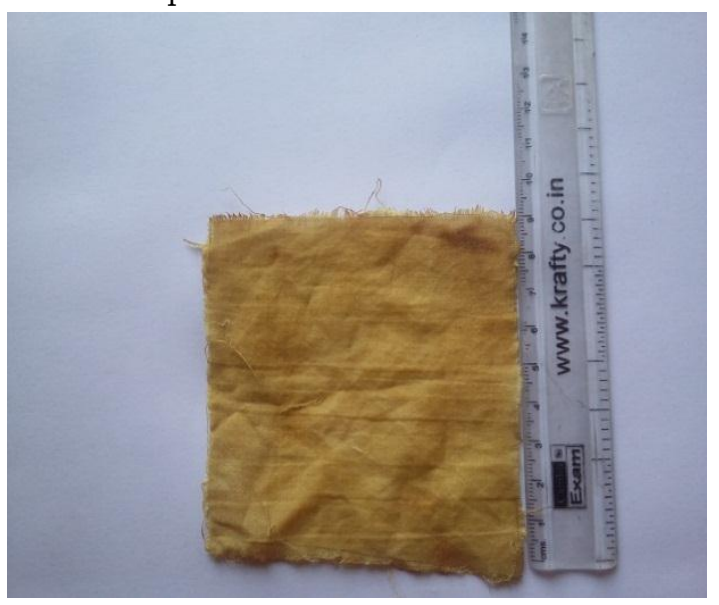

Method 1

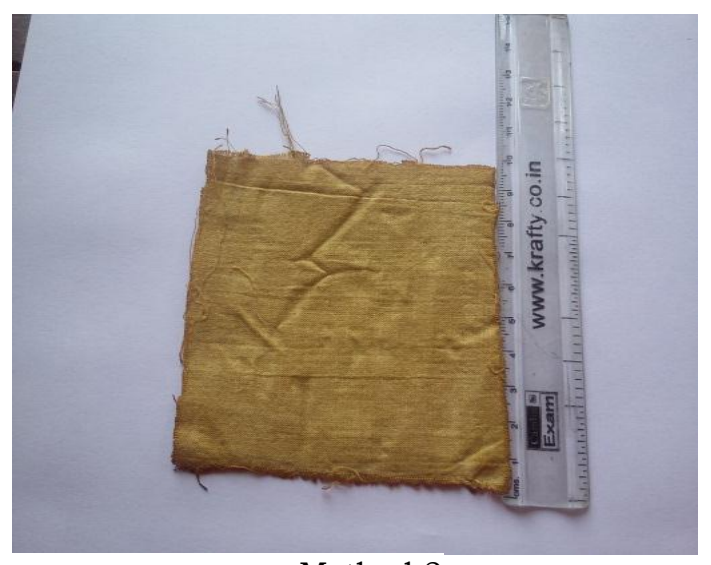

Method 2
This dye has no side effect on skin and it has no harmful effect on environment also. This process is economically viable as the raw materials are available at low cost and so cost of production is also very low.

Dye extracted from Thespesia populnea, Soland. (Family Malvaceae), is exploited particularly, in textile industry and believed to be superior for woolen and silk fabrics

\section{Conclusion:}

Textile industry was and is one of the largest industries in the world. Dyes can improve the socio economic status of a country. The colour extracted from plants and insects are nonhazardous and not harmful to the environment. This can improve our surroundings. Natural dyes are non-toxic to human and they are eco-friendly so we can use it in textile industry. Indigenous traditional knowledge on various resources including dye yielding plants is very essential for rural based development and future bioprospecting, provided proper precautionary measures are considered for sustainability, conservation and value based selection of the use pattern [1].

\section{References:}

1. Neha Grover and Vidya Patani; Extraction and application of natural dye preparations from the floral parts of Woodfordia fruticosa (Linn) Kurz, Indian Journal of Natural products and resources. Vol.2. (4), Dec.2011, pp: 403-408.

2. M. S. Papita Saha, Prof. S. Datta, Production of floral dye from different flowers available in west Bengal for textile and dye industry.

3. Chaitanya Lakshmi G. , Food colouring: The natural way, research Journal of chemical sciences, vol.4, (2),87-96, feb-2014.

4. Cooke T. The Flora of the presidency of Bombay, vol 1. 121, 1908

5. The wealth of India, Raw materials. CSIR, $17,8,1990$

6.http:/ / www.housebarra.com/EP/ep03/03dyes. html; 'Natural dyes', Dec 22,2003.

7. Mott Macdonald, project profile on natural food colours-marigold, annatto, iNDEX Tb (2000). 